Diabetologia 9, $161-164$ (1973)

(c) by Springer-Verlag 1973

\title{
Inhibition of Glucose Formation from Fructose by Phenformin in Perfused Guinea Pig Livers
}

\author{
R. Haeckel \\ Institut für Klinische Chemie Medizinische Hochschule Hannover \\ Received: August 23, 1972, accepted: December 11, 1972
}

Summary. Glucose formation from fructose was inhibited by $4 \times 10^{-5} \mathrm{~mol} / 1$ phenylethylbiguanide (DBI) in perfused guinea pig livers. The pattern of hepatic metabolite concentrations revealed a cross-over phenomenon between fructose and fructose-1-phosphate indicating that the phosphorylation of the substrate was influenced by the biguanide. It is suggested that this effect was due to a decrease of the ATP/ADP ratio observed in the presence of DBI.

Key words: Gluconeogenesis, phenformin, fructose, perfused guinea pig liver.

\section{Introduction}

The hypoglycaemic effect of biguanides may be due, at least partly, to an inhibition of gluconeogenesis [1-4]. Hepatic glucose formation from several substrates, as alanine $[5,6]$, lactate $[3,4]$, aspartate [7], glycerol [3] and fructose [8] is reduced by these compounds.

When lactate was used as the precursor for glucose output, phenylethylbiguanide, called DBI, affected the conversion of pyruvate to phosphoenolpyruvate [4]. It could not be inferred which step was primarily involved in the action of $\mathrm{DBI}$. In the presence of glycerol, Altschuld and Kruger [3] postulated that DBI reduces the intracellular ATP/ADP ratio, which may influence the phosphorylation of the substrate. These adenine nucleotides are also in equilibrium with AMP through the myokinase (EC 2.7.4.3.) reaction. Therefore, a rise of the intracellular AMP concentration may be expected under the influence of biguanides and this could affect the conversion of fructose-1,6diphosphate to fructose-6-phosphate, according to Patrick (9). Fructose-1,6-diphosphatase (EC 3.1.3.11) is greatly inhibited by AMP [10].

The following experiments were performed to find out which cytoplasmic reaction of the gluconeogenic pathway is influenced by DBI. As substrate for gluconeogenesis fructose, which is converted to glucose only in the cytosol, was used.

\section{Methods}

Male, albino guinea pigs $(300-350 \mathrm{~g})$ were fasted $48 \mathrm{~h}$, since we had found that the action of DBI increased with the time the animals had been starved prior to the perfusion experiments [8].

The perfusion medium consisted of $3 \mathrm{~g} / 100 \mathrm{ml}$ bovine albumin, $1 \mathrm{mg}$ sodium ampicillin and bovine erythrocytes washed three times and taken up in Krebs-Ringer bicarbonate solution (haemoglobin concentration: $5 \mathrm{~g} / 100 \mathrm{ml}$ ). $\mathrm{pH}$ was measured with an electrode installed in the reservoir and kept at 7.4, by the addition of sodium bicarbonate, because the effect of biguanides on gluconeogenesis is dependent on the extrahepatic hydrogen ion concentra- tion [11]. DBI was added $45 \mathrm{~min}$ and fructose $(15 \mathrm{mmol} / 1)$ $60 \mathrm{~min}$ after the liver was introduced into the perfusion system. After two hoursliver samples were taken by the method of Wollenberger et al. [12]. Hepatic metabolites were determined enzymatically in neutralized, perchloric acid extracts. Fructose-1-phosphate and the activity of fructokinase ( $\mathrm{EC}$ 2.7.1.3.) were measured according to Heinz [13], except that the concentration of fructose used by the crude enzyme preparation during the incubation was determined enzymatically [14]. The concentration of D-glyceraldehyde was estimated from the difference of the total aldehyde concentration [15] in the absence and presence of fructose, according to Heinz and Junghänel [16]. The assumption is made that the hepatic concentration of D-glyceraldehyde is normally extremely low.

The intracellular concentration of fructose was calculated according to Hohorst et al. [17] as follows:

$$
c_{i}=\frac{c_{t}-E \cdot c_{e}}{1-E}
$$

( $c_{i}$ means intracellular concentration, $c_{t}$ tissue concentration, E extracellular space and $c_{e}$ extracellular concentration). The tissue concentration was determined in a perchloric acid extract from liver samples taken by the freeze-stop technique [12]. For the estimation of the extracellular space inulin, which is known to be excluded from the intracellular compartment, was used. Inulin was measured enzymatically as fructosyl units [18] in a perchloric acid $(0.33 \mathrm{~mol} / \mathrm{l})$ extract of perfusate samples or of liver homogenate incubated at $80^{\circ} \mathrm{C}$ for $5 \mathrm{~min}$ and then neutralized with $\mathrm{K}_{2} \mathrm{CO}_{3}(5 \mathrm{~mol} / 1)$. The extracellular space $(\mathrm{ml} / \mathrm{g})$ was calculated as inulin space $E=c_{t} / c_{e}$. In this equation, formed in analogy to that derived by Morgan et al. [19] for the sorbitol space, $c_{t}$ means the inulin concentration of liver samples taken at the end of the perfusion experiment by the method of Wollenberger et al. [12], and $c_{e}$ the inulin concentration of the perfusate. $E$ was found to be $0.29 \pm 0.05(n=9)$.

All other experimental conditions were identical to those reported elsewhere in detail [4].

DBI was a gift of Vitamin and Pharmaceutical Corp. (Now York) and liver aldolase, prepared according to Dikow et al. [20] of Dr. F. Heinz (Medizinische Hochschule, D-3 Hannover).

\section{Results}

Isolated perfused livers from guinea pigs were used. These have been found very sensitive to the action of 
biguanides $[3,4]$. In this system, glucose formation from fructose was reduced about $65 \%$ by the addition of $4 \times 10^{-5} \mathrm{~mol} / \mathrm{L} \mathrm{DBI}$ (Fig. 1). When lactate was used as substrate for gluconeogenesis the same degree of inhibition was achieved by $2 \times 10^{-5} \mathrm{~mol} / \mathrm{l} \mathrm{DBI}$ under identical experimental conditions [4].

The pattern of hepatic metabolites revealed a cross-over phenomenon between the intracellular fructose and the fructose-1-phosphate concentration (Fig. 2) in the presence of $4 \times 10^{-5} \mathrm{~mol} / \mathrm{l}$ DBI. This effect was more pronounced with a higher concentration of the biguanide (Fig. 2). These findings indicated that the fructokinase reaction could have been affected by this compound. However, the activity of this enzyme was not influenced by DBI (up to $2 \mathrm{mmol} / \mathrm{l})$ in the $60000 \mathrm{~g}$ supernatant of a crude liver homogenate fraction. In the guinea pig liver the activity of this enzyme [21] was found to be $1.07 \pm 0.06$

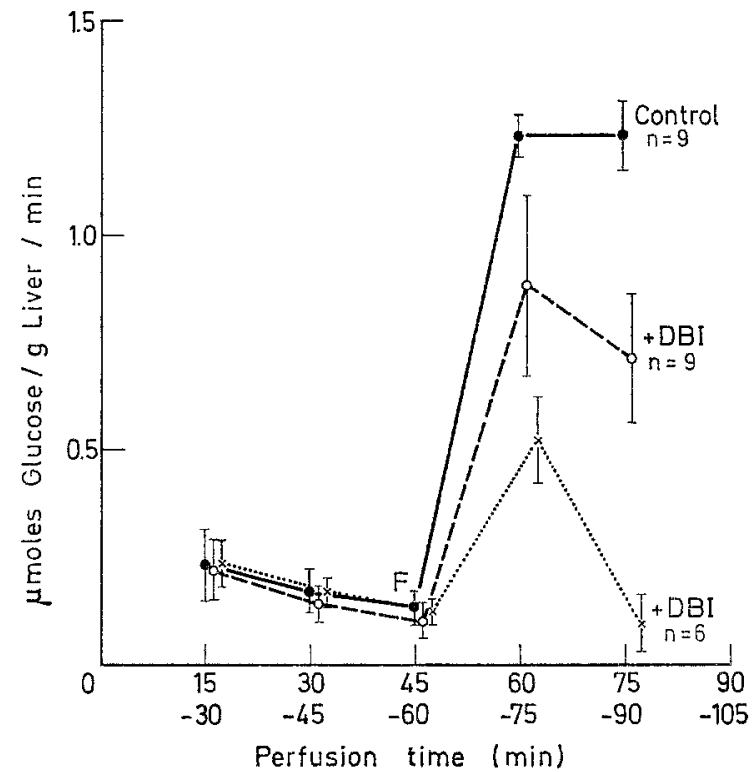

Fig. 1. The influence of $4 \times 10^{-5} \mathrm{~mol} / \mathrm{l}(\mathrm{O}-\mathrm{O})$ and $1 \times 10^{-4}$ $\mathrm{mol} / \mathrm{l}(\mathrm{x}-\mathrm{x})$ DBI on the rate of glucose formation from fructose $\left(1.5 \times 10^{-2} \mathrm{~mol} / \mathrm{l}\right)$ in perfused guinea pig livers. The addition of fructose (F) is marked by an arrow. Vertical bars represent standard deviations, the minimal number of contributing values are given in parentheses

$\mathrm{U} / \mathrm{g}$ wet weight $(n=4)$, which is about $50 \%$ of that measured in the rat organ [22].

From these results we assume that DBI affected the phosphorylation of fructose indirectly. This could have been achieved by a decreased intrahepatic ATP/ ADP ratio, as observed in the presence of DBI under the same experimental conditions (Table 1).

The phosphorylation product of fructose is cleaved in the cytoplasmic compartment of the liver cell to D-glyceraldehyde and dihydroxyacetone-phosphate. D-glyceraldehyde is converted to D-glyceraldehyde-3phosphate by triokinase (EC 2.7.1.28). In the rat liver fructose may also be partly converted to glycerate-2phosphate via glycerate-kinase (EC 2.7.1.,). In the guinea pig liver, however, fructose is probably introduced into the Embden-Meyerhof pathway mainly at the triose-phosphate level, because the hepatic activity of glycerate-kinase is hardly detectable in this species [4].

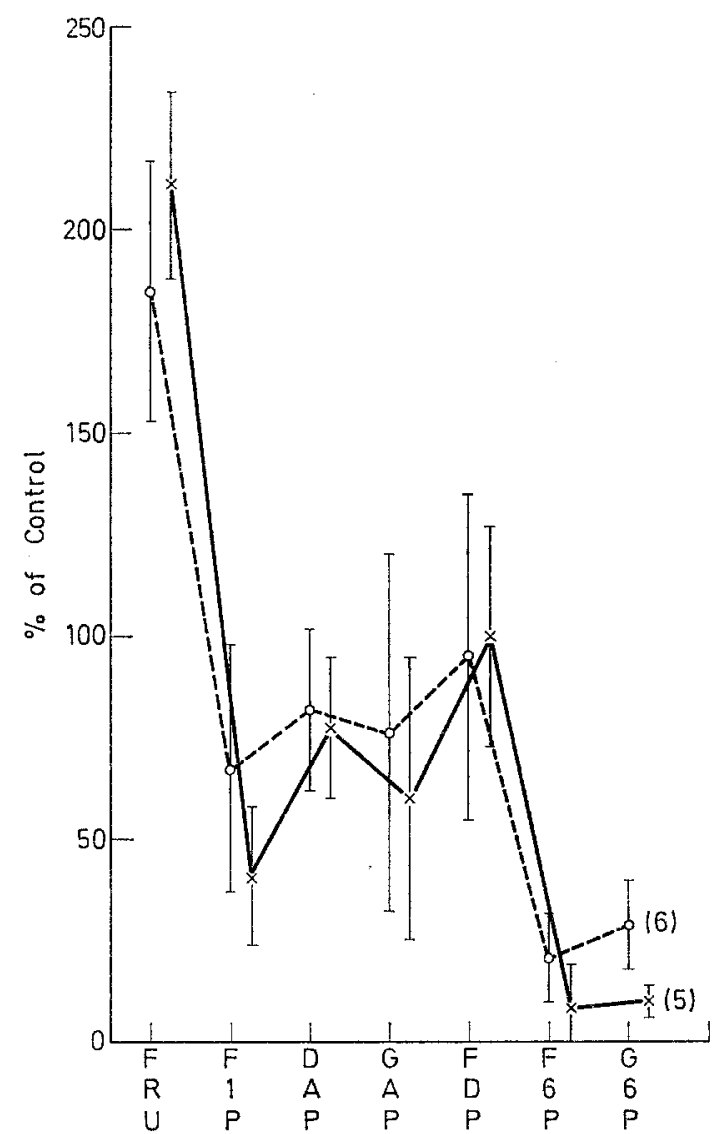

Fig. 2. Alterations of the hepatic metabolite concentrations in the presence of DBI: $4 \times 10^{-5} \mathrm{~mol} / \mathrm{l}(\mathrm{O}-\mathrm{O})$ and $1 \times 10^{-4} \mathrm{~mol} / 1 \mathrm{DBI}(\mathrm{x}-\mathrm{x})$. For further explanation see legend to Figure 1. The control values are given in Table 1.

Abbreviations: FRU fructose, F1P fructose-1-phosphate, GAP glyceraldehyde-3-phosphate, DAP dihydroxyacetonephosphate, FDP fructose-1,6-diphosphate, $\mathrm{F} 6 \mathrm{P}$ fructose-6-phosphate, G6P glucose-6-phosphate

Almost all metabolites beyond the phosphorylation of fructose were lowered if DBI was added to the perfusion medium. The ratio of fructose-1.6-diphosphate to fructose-6-phosphate was increased from 0.6 to 2.6 by $4 \times 10^{-5} \mathrm{~mol} / 1$ and to 7.3 by $1 \times 10^{-4} \mathrm{~mol} / 1$ DBI. The concentration of fructose-6-phosphate, glucose-6-phosphate and glycogen were markedly decreased in the presence of DBI (Fig. 2). The increase of the hepatic glycerol and glycerol-3-phosphate concentrations (Table 2) could be related to the accumulation of reducing equivalents, as indicated by the elevated lactate/pyruvate ratio (Table 3 ). 
Table 1. The influence of $D B I$ on the hepatic $A T P / A D P$ ratio

\begin{tabular}{llcc}
\hline DBI, & 0 & $4 \times 10^{-5}$ & $1 \times 10^{-4}$ \\
mol/1 & & & \\
\hline ATP & $2112,225(7)^{\mathrm{a}}$ & $1716,161(7)^{\mathrm{b}}$ & $1330,158(6)^{\mathrm{b}}$ \\
ADP & $573,63(7)$ & $950,128(7)^{\mathrm{b}}$ & $1071,98(6)^{\mathrm{b}}$ \\
ATP/ADP & $3.7,0.4(7)$ & $1.8,0.3(7)^{\mathrm{b}}$ & $1.2,0.2(6)^{\mathrm{b}}$ \\
\hline
\end{tabular}

a, b see Table 2 .

Table 2. The infuence of $D B I\left(10^{-4} \mathrm{~mol} / \mathrm{l}\right)$ on the metabolite concentrations of perfused guinea pig livers in the presence of fructose

\begin{tabular}{|c|c|c|c|c|}
\hline & Control & & DBI & \\
\hline Fructose & 2905,1246 & $(6)^{\mathrm{a}}$ & 6139,662 & $(5)^{\mathrm{b}}$ \\
\hline $\mathrm{F}-1-\mathrm{P}^{\mathrm{c}}$ & 2521,1001 & (6) & 942,420 & $(6)^{\mathrm{b}}$ \\
\hline Glyceraldehyde & 276 & (8) & 110 & (6) \\
\hline Glycerol & $53, \quad 39$ & (5) & 122,12 & $(5)$ \\
\hline DÄP & $49, \quad 10$ & (8) & 38,9 & (6) \\
\hline GAP & $17, \quad 7$ & (6) & 10,6 & (6) \\
\hline $\begin{array}{l}\text { Glycerol-3- } \\
\text { phosphate }\end{array}$ & $96, \quad 27$ & (7) & 418,59 & $(6)^{b}$ \\
\hline FDP & $22, \quad 14$ & (9) & 22 & (6) \\
\hline $\mathrm{F}-6-\mathrm{P}$ & 38 & (6) & 3 & $(5)^{b}$ \\
\hline $\mathrm{G}-6 \cdot \mathrm{P}$ & $100, \quad 37$ & (7) & 10,4 & $(5)^{\mathrm{b}}$ \\
\hline Glycogen & 1700,1090 & (5) & 255,144 & $(5)^{b}$ \\
\hline
\end{tabular}

a mean values in nmoles/g wet weight, with standard deviation and the number of contributing values in. parentheses.

$\mathrm{b}$ these values differ significantly $(P<0.05$, $t$-test $)$ from their corresponding controls.

c Abbreviations see legend to Fig. 2.

d A mean value of 156 nmoles/g liver $(n=6)$ was subtracted from the total aldehyde concentration as described under methods.

Table 3. The influence of DBI $\left(10^{-4} \mathrm{~mol} / \mathrm{l}\right)$ on the hepatic lactate/pyruvate ratio

\begin{tabular}{lrlrrr}
\hline & Control & \multicolumn{3}{c}{ DBI } \\
\hline Lactate & 528,217 & $(7)^{\mathrm{a}}$ & 1933,294 & $(5)^{\mathrm{b}}$ \\
Pyruvate & 45,14 & $(7)^{2}$ & 108,24 & $(5)^{\mathrm{b}}$ \\
Lactate/Pyruvate & 11, & 3 & $(7)$ & 18,22 & $(5)^{\mathrm{b}}$ \\
\hline
\end{tabular}

a, b See Table 2.

\section{Discussion}

The conversion of fructose to glucose (Fig. 1) and to glycogen (Table 2) occurs less rapidly in guinea pig livers compared with the perfused organ from rats $[6,23]$. This can be explained by a lower activity of hepatic fructokinase in the guinea pig. For the same reason fructose-1-phosphate accumulates to higher levels in livers from rats if saturating concentrations of fructose are present [16].

Altschuld and Kruger [3] postulated that the inhibition of gluconeogenesis in perfused guinea pig livers may be caused by a decrease of the ATP/ADP ratio. Our results give direct evidence to support this concept if fructose is used as substrate for gluconeogenesis.

The cross-over phenomenon between the intrahepatic fructose and fructose-1-phosphate concen- trations, observed in the presence of DBI, indicated that the phosphorylation rate of fructose was suppressed. Since the fructokinase reaction was not inhibited by DBI in a liver homogenate fraction, an indirect effect of this compound can be assumed. We suggest that this effect is caused by an alteration of the intrahepatic $\mathrm{ATP} / \mathrm{ADP}$ ratio, which is decreased by DBI. Whereas the phosphorylation rate of fructose is dependent on the ATP concentration, $\mathrm{ADP}$ is a strong inhibitor of fructokinase [24, 25].

The influence of DBI on the hepatic fructose-1.6diphosphate and fructose-6-phosphate concentrations may be explained by an altered $\frac{[\mathrm{ATP}] \cdot[\mathrm{AMP}]}{[\mathrm{ADP}]^{2}}$ ratio as already postulated by Patrick [9]. The intracellular AMP concentration was elevated in the presence of DBI under similar experimental conditions [26].

An influence of DBI on the triokinase activity should also be expected from the lowered ATP/ADP ratio. Although our data (Fig. 2) do not indicate such an effect, it cannot be excluded, since an increase of the concentration of glyceraldehyde could have been prevented for two reasons: $:^{1}$ because of an inhibition of the preceding fructokinase reaction by $\mathrm{DBI} ;{ }^{2}$ the accumulation of reducing equivalents (Table 3 , see also ref. 4) could have led to a shift versus glycerol, which was elevated under our experimental conditions (Table 2).

In conclusion, biguanides may primarily affect cellular respiration $[27-29]$, which causes an increase of reducing equivalents and a decrease of the ATP/ $\mathrm{ADP}$ ratio. In earlier studies [4] it was shown in perfused guinea pig livers that DBI reduced oxygen consumption and that gluconeogenesis from lactate was affected between pyruvate and phosphoenolpyruvate. The reason for the inhibition at this step could not be clarified.

Although no exact correlation was found between the ATP/ADP ratio and the suppression of gluconeogenesis from lactate by DBI [4], a causal relationship between these effects cannot be excluded. Measurements of the total tissue concentrations probably do not reflect the intramitochondrial ratio of these adenine nucleotides, which may be a sensitive regulator of the pyruvate carboxylation rate $[30,31]$. With fructose, some evidence was found that in the presence of DBI the conversion of this substrate to glucose could be affected by an altered ATP/ADP ratio.

Acknowledgement. This work was supported by the Deutsche Forschungsgemeinschaft, Bad Godesberg. Excellent technical assistance was thankfully accepted from Mrs. U. Strewe.

\section{Literature}

1. Nielsen, R.I., Swanson, H. E., Tanner, D. C., Williams, R.H., O'Connel, M.: Effects on blood sugar of a now potent hypoglycemic compound. Arch intern. Med. $101,211-215(1958)$ 
2. Beringer, A.: Zur Behandlung der Zuckerkrankheit bei Biguaniden, Wien. med. Wschr. 108, 880-882 (1958).

3. Altschuld, R.A., Kruger, F.A.: Inhibition of hepatic gluconeogenesis in guinea pig by phenformin, Ann. N. Y. Acad. Sci. 148,612-622 (1968).

4. Haeckel, R., Haeckel, H.: Inhibition of Gluconeogenesis from lactate by Phenylethylbiguanide in the perfused Guinea pig liver. Diabetologia 8, 117-124 (1972).

5. Sandler, R., Vimick, L., Freinkel, N.: Interrelationships between phenformin and ethanol in obesity. Diabetes 16, 508 (1967).

6. Haeckel, R., Haeckel, H.: Interference of ethanol oxidation with gluconeogenesis in the perfused guinea pig liver. Biochemistry 7, 3803-3810 (1968).

7. Mayer, F., Ipaktchi, M., Clauser, H.: Specific inhibition of gluconeogenesis by biguanides. Nature 213, $203-205$ (1967).

8. Haeckel, R., Haeckel, H.: On the inhibition of gluconeogenesis by 1- $\beta$-phenyl-ethylbiguanide in the perfused guinea pig liver. In (H.D. Söling, B. Willms, eds.) "Regulation of Gluconeogenesis", 127-139. Stuttgart: Thieme Verlag 1971.

9. Patrick, S.J.: Effect of phenformin and hypoglycin on gluconeogenesis of rat tissues: Canad. J. Biochem. 44, $27-33$ (1966).

10. Underwood, A.H., Newsholme, E. A. : Some properties of fructose-diphosphatase of rat liver and their relation to the control of gluconeogenesis. Biochem. J. 95, 767-774 (1965).

11. Haeckel, R., Haeckel, H., Anderer, M.: The influence of extracellular hydrogen ions on the inhibition of gluconeogenesis by butylbiguanide in the perfused guinea pig liver, Biochem. Pharmacol. 20, 1053-1060 (1971)

12. Wollenberger, A., Krause, E.G., Mahler, B.E.: Orthophosphat- und Phosphatkreatingehalt des Herzmuskels. Naturwissenschaften 45, 294-295 (1958).

13. Heinz, F.: Enzymatische Bestimmung von fructose-lphosphat. Z. physiol. Chem. 349, 859-860 (1968).

14. Schmidt, F.H.: Die enzymatische Bestimmung von Glucose und Fructose nebeneinander. Klin. Wschr. 39, $1244-1247$ (1961).

15. Holzer, H., Goedde, H. W., Schneider, S. : Umsatz von Oxybrenztraubensäure und Glykolaldehyd mit Carboxylase und Alkoholdehydrogenase aus Hefe. Biochem. Z. 327, 245-254 (1955).

16. Heinz, F., Junghänel, J. : Metabolitmuster in Rattenleber nach Fructoseapplikation. Z. physiol. Chem. $\mathbf{3 5 0}, 859-866(1969)$.
17. Hohorst. H.J., Kreutz, F.H., Bücher, Th.: Über Metabolitgehalte und Metabolit-Konzentrationen in der Leber der Ratte. Biochem. Z. 332, 18-46 (1959).

18. Renschler, H.E.: Die Anwendung enzymatischer Methoden zur Bestimmung von Inulin. Klin. Wschr. 41, 615-618 (1963).

19. Morgan, H.E., Henderson, M.J., Regen, D.M. Park, C.P.: Regulation of Glucose uptake in muscle. J. Biol. Chem. 236, 253-261 (1961).

20. Dikow, A. L., Jeckel, D., Pfleiderer, G. : Isolierung und Charakterisierung von Aldolase A, B und C aus menschlichen Organen. Z. physiol. Chem. 352, 1151 $1156(1971)$.

21. Heinz, F., Haeckel, F., unpublished results.

22. Heinz, F., Lamprecht, W.: Enzyme des Fructosestoffwechsels Z. physiol. Chem. 348, 855-863 (1967).

23. Söling, H.D., Willms, B., Kleinecke, J., Gehlhoff, M. : Regulation of gluconeogenesis in the guinea pig liver. Eur. J. Biochem. 16, 289-302 (1970).

24. Parks, R.E., Ben-Gershom, E., Lardy, H.A.: Liver fructokinase. J. Biol. Chem. 227, 231-242 (1957).

25. Sanchez, J.J., Gonzales, N.S., Pontis, H.G.: Fructokinase from rat liver. Biochim. Biophys. Acta 227, $67-78(1971)$

26. Haeckel, R.: Untersuchungen über die Wirkung von blutzuckersenkenden Biguaniden auf die hepatische Gluconeogenese. Habilitationsschrift (1971), Medizinische Hochschule Hannover.

27. Pressmann, B.C.: The effects of guanidine and alkyl guanidines on the energy transfer reactions of mitochondria. J. biol. Chem. 238, 401-409 (1963).

28. Schäfer, G.: Site spencific uncoupling and inhibition of oxidative phosphorylation by biguanides, Biochem. biophys. Acta 172, 334-337 (1969).

29. Davidoff, F.: Effects of guanidine derivatives on mitochondria function. J. Biol. Chem. 246, 40174027 (1971).

30. Keech, D.B., Utter, M. F.: Pyruvate carboxylase II. Properties. J. Biol. Chem. 238, 2609-2614 (1963).

31. Stucki, J. W., Brawald, F., Walter, P.: Regulation of pyruvate metabolism in rat liver mitochondria by adenine nucleotides and fatty acids. Eur. J. Biochem. 27, 181-191 (1972).

Priv.-Doz. Dr. R. Haeckel

Med. Hochschule

Institut für Klinische Chemie

D-3 Hannover-Krefeld

Postfach 180

Federal Republic of Germany 